\title{
DESEMPENHO DE SEMENTES DE ALGODÃO APÓS O PROCESSAMENTO E ARMAZENAMENTO ${ }^{1}$
}

\author{
JOSIAS CONCEIÇÃODASILVA², MARIACRISTINAALBUQUERQUE ${ }^{3}$, ELISABETHAPARECIDAFURTADO DE MENDONÇA4 ${ }^{4}$, MICHELYELIANE KIM ${ }^{4}$
}

\begin{abstract}
RESUMO - O trabalho foi realizado com o objetivo de estudar os efeitos do processamento e armazenamento na qualidade de sementes de algodão, cultivar ITA 90-2, produzidas em Campo Verde-MT, nos anos agrícolas de 2001 e 2002. As sementes foram analisadas antes e após cada etapa do processamento e durante o armazenamento. O delineamento experimental foi o inteiramente casualizado, com quatro repetições. Os tratamentos foram constituídos das etapas do processamento: antes e após a colheita mecânica, após 30, 60 e 85 dias de armazenamento em fardo no campo, após descaroçamento mecânico, após deslintamento químico, após beneficiamento em mesa de gravidade e após 15, 30, 6090 e 120 dias de armazenamento. No ano de 2002 foram apenas 30 dias de armazenamento. As médias foram comparadas pelo teste de Scott-Knott a 5\%. Os resultados obtidos permitem concluir que o armazenamento temporário, em fardos no campo, por até 85 dias, não causa perda imediata na qualidade das sementes; o descaroçamento mecânico não tem efeito prejudicial imediato sobre o vigor das sementes e a porcentagem de germinação mantémse dentro do padrão $(70 \%)$ para o comércio de sementes por até seis meses após a colheita.
\end{abstract}

Termos para indexação: Gossypium hirsutum, deslintamento, germinação, vigor.

\section{COTTON SEED PERFORMANCEAFTER PROCESSINGAND STORAGE}

\begin{abstract}
The aim of this study was to evaluate the effects of processing and storage on the physiological quality of cotton seeds, cultivar ITA 90-2, produced in Campo Verde, during the 2001 and 2002 cropping seasons. The seeds were collected, pitted and delinted with sulfuric acid and were analyzed with regard to their physiological quality at all the stages of the experiment. A completely randomized experimental design was employed and the means were compared by the Scott- Knott's test at 5\%. The experiment consisted of 13 treatments and four replications. Based on the results obtained, we can conclude that cotton seeds stored as bales, in the field, for up to 85 days are not subject to an immediate loss in seed quality; mechanical processing does not have an immediate harmful effect on seed vigor and the germination percentage can be maintained within the acceptable standard for seed commercialization (70\%) for up to six months after harvesting.
\end{abstract}

Index terms: Gossypium hirsutum, delinting, germination, vigor.

\section{INTRODUÇÃO}

O processamento de sementes de algodão envolve etapas diferenciadas como descaroçamento e deslintamento, além do armazenamento temporário no campo, que podem causar danos mecânicos e efeitos imediatos e latentes na sua

\footnotetext{
${ }^{1}$ Submetido em 06/08/2004. Aceito para publicação em 31/03/2005. Parte da Dissertação de Mestrado em Agricultura Tropical do primeiro autor. Projeto financiado pelo CNPq;

${ }^{2}$ Professor do Centro Federal de Tecnologia, CEFET, Cuiabá-MT;
}

qualidade. Queiroga e Beltrão (1999) citam que o roteiro do algodão em caroço entre o campo e a usina consiste em: colheita, armazenamento temporário por um mês no campo, transporte, armazenamento temporário por três meses na usina em forma de tulhas, transporte e beneficiamento em descaroçadores de serra ou de rolo. Além destas etapas, as

\footnotetext{
${ }^{3} \mathrm{Dr}^{\mathrm{a}}$, Departamento de Fitotecnia e Fitossanidade, Faculdade de Agronomia e Medicina Veterinária, UFMT, Cuiabá-MT, 78060-900, mcfa@cpd.ufmt.br;

${ }^{4}$ Discente do Curso de Agronomia, bolsista PIBIC/UFMT. Cuiabá-MT, 78060-900.
} 
sementes ainda são deslintadas e armazenadas até a próxima semeadura.

Se forem feitos fardos prensados após a colheita Silva (1998) comenta que estes não devem permanecer no campo por mais de 72 horas, pois as sementes podem aquecer, diminuindo o vigor e a germinação. Se as sementes possuem menos que $13 \%$ de umidade, após o descaroçamento, podem ficar armazenadas a granel ou em "bags" em local arejado, desde que a região não tenha características de altas temperaturas e umidade relativa.

Também, durante o armazenamento temporário, o línter presente nas sementes de algodão pode constituir-se em importante veículo de disseminação de patógenos, que pode comprometer o sucesso da cultura. Além de abrigar muitos patógenos, o línter favorece a presença de fungos saprófitas que podem dificultar a detecção de microrganismos importantes (Lima et al., 1982; Furlan et al., 1986). Assim, o deslintamento melhora a qualidade fisiológica das sementes, pois reduz os microrganismos que se encontram na superfície das mesmas (Tanaka e Paolinelli, 1984).

No estado do Mato Grosso, as sementes de algodão são colhidas nos meses de junho a agosto. Após a colheita, estas são deixadas no campo por um determinado período, que pode variar de poucos dias a meses, em fardos cobertos com lona plástica, até o momento do processamento. Apesar das condições climáticas nesse período serem amenas, as variações de temperatura e umidade relativa do ar e juntamente com os danos causados pelo descaroçamento mecânico podem aumentar o metabolismo das sementes e fungos associados, causar redução do vigor e acelerar o processo de deterioração das sementes durante o armazenamento.

Após o deslintamento e a classificação, as sementes são embaladas em sacaria de papel e armazenadas. O Serviço de Produção de Sementes Básicas da Embrapa Algodão, em Campina Grande-PB, recomenda o armazenamento das sementes de algodão por no máximo oito meses, nas condições ambientais (valores médios de $26,9^{\circ} \mathrm{C}$ e $57 \%$ UR) e com teor de água abaixo de 10\% (Queiroga e Beltrão, 1999). Quando as sementes de algodoeiro são armazenadas em ambientes de alta umidade relativa, deterioram em curto espaço de tempo, apresentando germinação reduzida à metade após 30 dias de armazenagem.

Ao armazenarem sementes de algodão, cultivar IAC-20, em câmara fria e condições não controladas, Medeiros Filho et al. (1996) verificaram que as sementes ao serem armazenadas em ambiente sem controle de temperatura e umidade relativa, ocorreu redução significativa da germinação e do vigor, após quatro meses de armazenamento. Pádua e Vieira (2001) também verificaram decréscimos significativos na germinação de sementes deslintadas de algodoeiro, cultivar DeltaPine AC-90, armazenadas em ambiente sem controle de temperatura e umidade relativa, sendo tal redução mais acentuada em sementes não tratadas com fungicida e nas de baixo vigor. As sementes com baixo vigor apresentaram perda significativa na germinação, a partir do segundo mês de armazenamento e as de alto vigor apresentaram valores de germinação acima dos padrões mínimos para comercialização até dez meses de armazenamento.

Desta forma, este trabalho foi realizado com o objetivo de estudar os efeitos das etapas do processamento, da colheita até o armazenamento, sobre a qualidade fisiológica de sementes de algodão, na região de Campo Verde-MT.

\section{MATERIAL E MÉTODOS}

O trabalho foi desenvolvido na Algodoeira Campo Verde, situada no município de Campo Verde-MT; no Centro Federal de Educação Tecnológica de Cuiabá (CEFET Cuiabá), em São Vicente da Serra ( $86 \mathrm{~km}$ de Cuiabá) e no Laboratório de Sementes da Faculdade de Agronomia e Medicina Veterinária (FAMEV) da Universidade Federal de Mato Grosso (UFMT), nos anos de 2001 e 2002. A área de cultivo localiza-se no município de Campo Verde-MT, 732m de altitude, latitude $15^{\circ} 30^{\prime} \mathrm{S}$ e longitude $55^{\circ} 08^{\prime} \mathrm{W}$.

Foram utilizadas sementes de algodão, cultivar ITA-90, semeadas no mês de dezembro de 2000 (ano agrícola 2001) e de 2001 (ano agrícola 2002). A colheita foi realizada em junho de 2001 e em julho de 2002, quando as sementes apresentavam teor de água inferior a 9,0\%, utilizando colhedora automotriz John Deere 9960. Após a colheita mecânica, o algodão em caroço foi prensado, formando os fardos que foram cobertos com lonas plásticas brancas e deixados no campo durante 85 dias. Nesse período, as médias de temperatura e umidade relativa do ar variaram, em 2001, de 25,5 a $29,5^{\circ} \mathrm{C}$ e de 45 a $70 \%$ e, em 2002 , de 23,2 a $29,0^{\circ} \mathrm{C}$ e de 43 a $75 \%$.

Aos 85 dias de armazenamento no campo, o fardo de sementes foi encaminhado para a usina de processamento, em Campo Verde-MT, onde foi realizado o descaroçamento mecânico, em máquina descaroçadeira de serras. As sementes foram submetidas ao deslintamento químico comercial, utilizando-se ácido sulfúrico concentrado na dose de $0,15 \mathrm{~L} . \mathrm{kg}^{-}$ ${ }^{1}$ de sementes por três minutos. Depois, as sementes foram lavadas em água corrente e neutralizadas com solução de 
carbonato de sódio, na proporção de $1 \mathrm{~kg}$ de carbonato de sódio para cada 10L de água. Na seqüência, as sementes foram lavadas, secas ao sol e beneficiadas em mesa de gravidade. A seguir, as sementes foram embaladas em sacos de papel multifoliado com capacidade de $25 \mathrm{~kg}$ e colocadas em armazém convencional, sobre estrados de madeira, na Algodoeira Campo Verde, onde permaneceram durante os meses de outubro de 2001 a março de 2002 e de outubro a dezembro de 2002.

Foram coletadas amostras de sementes antes e após a colheita e aos 30, 60 e 85 dias de armazenamento em fardos no campo, antes e após as etapas de descaroçamento, deslintamento, beneficiamento em mesa de gravidade e a 15 , 30, 60, 90 e 120 dias de armazenamento. No ano de 2002, as sementes foram armazenadas somente por 30 dias. As sementes foram encaminhadas ao Laboratório de Sementes da FAMEV/UFMT e ao CEFET-Cuiabá, onde foram analisadas. As sementes coletadas antes da operação de deslintamento foram colocadas em ácido sulfúrico concentrado (98\%), na proporção de uma parte de ácido para duas partes de sementes.

Todas as amostras de sementes foram homogeneizadas e submetidas aos seguintes testes: teor de água, germinação, primeira contagem de germinação, emergência de plântulas em areia, envelhecimento acelerado, emergência de plântulas em campo, índice de velocidade de emergência e sanidade.

O teor de água foi determinado de acordo com as Regras para Análise de Sementes-RAS (Brasil, 1992). Para o teste de germinação e primeira contagem de germinação (Brasil, 1992; Nakagawa, 1994) foram utilizadas quatro subamostras de 50 sementes, colocadas em substrato papel germitest, umedecido em água destilada, na quantidade de duas e meia vezes o peso do papel seco. Os rolos foram mantidos em germinador a $25^{\circ} \mathrm{C}$. As avaliações foram feitas após quatro e 12 dias, sendo os resultados expressos em porcentagem de plântulas normais.

Para o teste de emergência de plântulas em areia, quatro subamostras de 50 sementes foram semeadas em areia colocada em caixas plásticas, dimensões de 26,0x15,5x8,0cm, deixadas em ambiente com temperatura média de $28,6^{\circ} \mathrm{C}$. O umedecimento inicial da areia correspodeu a $60 \%$ da capacidade de retenção e o reumedecimento foi realizado sempre que necessário. A avaliação foi feita após sete dias, contando-se as plântulas normais emergidas (Brasil, 1992).

No teste de envelhecimento acelerado foi utilizado o método da caixa de plástico, tipo gerbox (mini-câmara), com as sementes distribuídas em camada única sobre a bandeja de tela de alumínio. No interior do gerbox foi colocada lâmina de água de $40 \mathrm{~mL}$. As caixas foram levadas à câmara B.O.D., regulada a $41 \pm 1^{\circ} \mathrm{C}$ por 60 horas (Marcos Filho, 1999). Após, foram colocadas para germinar e avaliadas aos cinco dias após a semeadura.

O teste de emergência de plântulas em campo foi instalado com quatro subamostras de 50 sementes, dispostas em sulcos com 2,5 metros de comprimento, espaçados de 0,5 metro, a cinco centímetros de profundidade. Após 14 dias, as plântulas normais emergidas foram contadas e os resultados expressos em porcentagem (Nakagawa, 1994). Foram consideradas como plântulas normais emergidas aquelas com os cotilédones inteiramente acima do solo. Juntamente com esse teste foram realizadas avaliações diárias para o cálculo do índice de velocidade de emergência de plântulas (Maguire, 1962).

A determinação da ocorrência de fungos nas sementes foi realizada no Laboratório de Fitopatologia da FAMEV/UFMT. Utilizou-se o método do papel de filtro proposto por Neegaard (1977), com 20 subamostras de 10 sementes, em caixas de plástico contendo três folhas de papel de filtro previamente esterilizadas, embebidas em água destilada. As caixas foram colocadas em ambiente com temperatura de $22 \pm 2^{\circ} \mathrm{C}$, sob regime de doze horas de luz/escuro. Após 24 horas, foram acondicionadas em "freezer" a $-18^{\circ} \mathrm{C}$, onde permaneceram por 24 horas e, depois, colocadas para incubação por mais cinco dias nas condições anteriormente descritas. Após o período de incubação, as sementes foram examinadas individualmente, sob microscópio estereoscópico, anotandose a porcentagem de ocorrência de fungos.

Durante o período de execução do experimento, foram coletados os valores diários de temperatura e umidade relativa do ar, na Estação Meteorológica de São Vicente, localizada nas coordenadas de latitude $15^{\circ} 49^{\prime} 07^{\prime \prime S}$ e longitude $55^{\circ} 25^{\prime} 02^{\prime \prime} \mathrm{W}$. No armazém, nos meses de novembro de 2001 a março de 2002 e de outubro a dezembro de 2002, foram registradas diariamente as temperaturas máxima, mínima e média.

O delineamento experimental utilizado foi o inteiramente casualizado, com 13 e 10 tratamentos, respectivamente para os anos agrícolas de 2001 e 2002, e quatro repetições. Para cada ano agrícola, foi realizada a análise de variância nos dados das características estudadas, exceto para o teor de água e sanidade das sementes, usando-se o programa estatístico SAEG, da Universidade Federal de Viçosa-UFV. Quando necessário, os resultados foram transformados para arc $\operatorname{sen} \sqrt{x / 100}$. As médias foram comparadas pelo teste de Scott-Knott a 5\% de probabilidade (Borges e Ferreira, 2002). 


\section{RESULTADOS E DISCUSSÃO}

Nas Tabelas 1 e 2, encontram-se os resultados médios das análises realizadas com as sementes de algodoeiro nos anos agrícolas de 2001 (Tabela 1) e 2002 (Tabela 2). Verificouse efeito altamente significativo das etapas do processamento na germinação e no vigor das sementes. $\mathrm{O}$ teor de água das sementes variou, em função da umidade relativa e da temperatura do ar, de 8,3 até $11,8 \%$ em 2001 , e de 7,4 a $10,4 \%$ em 2002, que são teores adequados para a conservação das sementes.

Observa-se que a porcentagem de germinação permaneceu entre 90 e $97 \%$ (Tabela 1) e entre 85 e 99\% (Tabela 2), no período entre a colheita e o início do armazenamento, valores superiores a porcentagem mínima para comercialização de sementes de algodoeiro em Mato Grosso, que é de 70\% (Mato Grosso, 1998). O armazenamento temporário do algodão em caroço no campo, durante 85 dias, em fardos cobertos por lonas plásticas, não prejudicou a germinação, provavelmente devido o teor de água das sementes ter permanecido abaixo de $11 \%$, à temperatura entre 27 e $29^{\circ} \mathrm{C}$ e a umidade relativa do ar abaixo de $70 \%$, condições consideradas adequadas para conservação de sementes por períodos curtos. Freire et al. (1999) afirmaram que, em condições de Cerrado, baixa umidade predominante no inverno (entre 30 e 40\%), as sementes de algodão podem ser armazenadas no campo por curto período (dois a três meses) sem perda de germinação. De forma contrária, Silva (1998) recomenda que os fardos prensados não devem permanecer no campo por mais de 72 horas porque poderá haver aquecimento das sementes, diminuindo sua germinação e vigor. As etapas após descaroçamento e beneficiamento em mesa de gravidade proporcionaram decréscimos significativos na germinação das sementes somente no ano agrícola de 2002 (Tabela 2).

Após 15 dias de armazenamento convencional (Tabela 1), a porcentagem de germinação das sementes teve redução significativa, passando de 90 para $79 \%$. Até os 60 dias de armazenamento os resultados não variaram, mas aos $90 \mathrm{e}$ 120 dias ocorreram reduções de 60 e de 87 pontos percentuais na porcentagem de germinação, respectivamente. As temperaturas altas no armazém, acima de $25^{\circ} \mathrm{C}$, em fevereiro de 2002 , e de $35^{\circ} \mathrm{C}$, em março de 2002, a umidade relativa do ar acima de $80 \%$ e a alta incidência de fungos (Soave, 1985) no início do armazenamento favoreceram a redução da qualidade das sementes no ano agrícola de 2001 após 90 dias. Na segunda safra analisada (Tabela 2), as sementes ficaram armazenadas por 30 dias, observando-se também redução significativa na germinação das sementes em relação às etapas anteriores.

Os valores percentuais do teste de emergência de plântulas em areia (Tabela 1), permaneceram inalterados no período compreendido entre a colheita e o descaroçamento, variando de 98 a 96\%. Na safra seguinte (Tabela 2), ocorreram

TABELA 1. Médias de teor de água (TA), teste de germinação (TPG), emergência de plântulas em areia (GA) e de testes de vigor (primeira contagem-PC, envelhecimento acelerado-EA, emergência de plântulas-EC e índice de velocidade de emergência no campo-IVE) em todas as etapas do processamento de sementes de algodão. Ano agrícola 2001.

\begin{tabular}{|c|c|c|c|c|c|c|c|}
\hline \multirow{2}{*}{ Etapas do Processamento } & TA & $\mathrm{TPG}^{1}$ & GA & $\mathrm{PC}^{1}$ & EA & EC & \multirow{2}{*}{ IVE } \\
\hline & \multicolumn{6}{|c|}{$-\ldots \ldots$} & \\
\hline Antes da colheita & 8,3 & $97 \mathrm{~A}$ & $98 \mathrm{~A}$ & $80 \mathrm{~B}$ & $96 \mathrm{~A}$ & $80 \mathrm{~A}$ & $5,1 \mathrm{~B}$ \\
\hline Após colheita mecânica & 10,7 & $93 \mathrm{~A}$ & $96 \mathrm{~A}$ & $78 \mathrm{~B}$ & $94 \mathrm{~A}$ & $75 \mathrm{~B}$ & $4,6 \mathrm{~B}$ \\
\hline Após 30 dias de armazenamento em fardo & 8,8 & $93 \mathrm{~A}$ & $94 \mathrm{~A}$ & $93 \mathrm{~A}$ & $92 \mathrm{~A}$ & $95 \mathrm{~A}$ & 7,9 A \\
\hline Após 60 dias de armazenamento em fardo & 9,1 & $94 \mathrm{~A}$ & $95 \mathrm{~A}$ & $93 \mathrm{~A}$ & $90 \mathrm{~A}$ & $98 \mathrm{~A}$ & $9,7 \mathrm{~A}$ \\
\hline Após 85 dias de armazenamento em fardo/antes descaroçamento & 9,4 & $96 \mathrm{~A}$ & $94 \mathrm{~A}$ & $94 \mathrm{~A}$ & $93 \mathrm{~A}$ & $89 \mathrm{~A}$ & $9,0 \mathrm{~A}$ \\
\hline Após o descaroçamento/antes deslintamento & 10,1 & $95 \mathrm{~A}$ & $96 \mathrm{~A}$ & $92 \mathrm{~A}$ & $89 \mathrm{~A}$ & $95 \mathrm{~A}$ & $11,6 \mathrm{~A}$ \\
\hline Após deslintamento/antes classificação & 9,3 & $91 \mathrm{~A}$ & $65 \mathrm{~B}$ & $90 \mathrm{~A}$ & $60 \mathrm{C}$ & $95 \mathrm{~A}$ & $12,5 \mathrm{~A}$ \\
\hline Após o beneficiamento/tempo zero de armazenamento & 10,1 & $90 \mathrm{~A}$ & $56 \mathrm{C}$ & $88 \mathrm{~A}$ & $73 \mathrm{~B}$ & $85 \mathrm{~A}$ & $6,9 \mathrm{~B}$ \\
\hline 15 dias de armazenamento & 9,9 & $79 \mathrm{~B}$ & $52 \mathrm{C}$ & $74 \mathrm{~B}$ & $44 \mathrm{D}$ & $93 \mathrm{~A}$ & $9,7 \mathrm{~A}$ \\
\hline 30 dias de armazenamento & 10,8 & $74 \mathrm{~B}$ & - & $71 \mathrm{~B}$ & $33 \mathrm{D}$ & $68 \mathrm{~B}$ & $8,3 \mathrm{~A}$ \\
\hline 60 dias de armazenamento & 11,8 & $74 \mathrm{~B}$ & $68 \mathrm{~B}$ & $74 \mathrm{~B}$ & $5 \mathrm{E}$ & $59 \mathrm{~B}$ & $6,3 \mathrm{~B}$ \\
\hline 90 dias de armazenamento & 10,9 & $36 \mathrm{C}$ & $63 \mathrm{~B}$ & $36 \mathrm{C}$ & $2 \mathrm{E}$ & - & - \\
\hline 120 dias de armazenamento & 10,5 & $12 \mathrm{D}$ & $43 \mathrm{D}$ & $12 \mathrm{D}$ & $3 \mathrm{E}$ & $55 \mathrm{~B}$ & $4,5 \mathrm{~B}$ \\
\hline Coeficiente de variação (\%) & 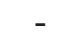 & 6,33 & 4,73 & 6,33 & 8,81 & 18,29 & 32,39 \\
\hline
\end{tabular}

Médias seguidas da mesma letra maiúscula na coluna, não diferem entre si pelo teste de Scott-Knott a 5\%. 
TABELA 2. Médias de teor de água (TA), teste de germinação (TPG), emergência de plântulas em areia (GA) e de testes de vigor (primeira contagem-PC, envelhecimento acelerado-EA, emergência de plântulas-EC e índice de velocidade de emergência no campo-IVE) em todas as etapas do processamento de sementes de algodão. Ano agrícola 2002.

\begin{tabular}{|c|c|c|c|c|c|c|c|}
\hline \multirow[b]{2}{*}{ Etapas do Processamento } & TA & TPG & GA & $\mathrm{PC}$ & EA & $\mathrm{EC}$ & \multirow[b]{2}{*}{ IVE } \\
\hline & \multicolumn{6}{|c|}{ 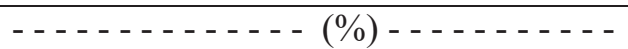 } & \\
\hline Antes da colheita & 7,4 & $97 \mathrm{~A}$ & $95 \mathrm{~A}$ & $92 \mathrm{~B}$ & $95 \mathrm{~A}$ & $88 \mathrm{~B}$ & $10,14 \mathrm{~B}$ \\
\hline Após colheita mecânica & 8,6 & $95 \mathrm{~A}$ & $95 \mathrm{~A}$ & $94 \mathrm{~B}$ & $94 \mathrm{~A}$ & $91 \mathrm{~A}$ & $10,39 \mathrm{~B}$ \\
\hline Após 30 dias de armazenamento em fardo & 8,8 & $99 \mathrm{~A}$ & $88 \mathrm{~B}$ & $99 \mathrm{~A}$ & $99 \mathrm{~A}$ & $96 \mathrm{~A}$ & $11,07 \mathrm{~A}$ \\
\hline Após 60 dias de armazenamento em fardo & 8,1 & $98 \mathrm{~A}$ & $97 \mathrm{~A}$ & $98 \mathrm{~A}$ & $94 \mathrm{~A}$ & $92 \mathrm{~A}$ & $11,52 \mathrm{~A}$ \\
\hline Após 85 dias de armazenamento em fardo/antes descaroçamento & 10,4 & $95 \mathrm{~A}$ & $91 \mathrm{~B}$ & $94 \mathrm{~B}$ & $90 \mathrm{~B}$ & $92 \mathrm{~A}$ & $11,39 \mathrm{~A}$ \\
\hline Após o descaroçamento/antes deslintamento & 10,0 & $85 \mathrm{~B}$ & $82 \mathrm{C}$ & $82 \mathrm{C}$ & $66 \mathrm{D}$ & $88 \mathrm{~B}$ & $10,83 \mathrm{~A}$ \\
\hline Após deslintamento/antes classificação & 9,8 & $93 \mathrm{~A}$ & $87 \mathrm{~B}$ & $92 \mathrm{~B}$ & $85 \mathrm{~B}$ & $83 \mathrm{~B}$ & $10,28 \mathrm{~B}$ \\
\hline Após o beneficiamento/tempo zero de armazenamento & 10,0 & $88 \mathrm{~B}$ & $71 \mathrm{D}$ & $86 \mathrm{C}$ & $77 \mathrm{C}$ & $86 \mathrm{~B}$ & $10,94 \mathrm{~A}$ \\
\hline 15 dias de armazenamento & & $86 \mathrm{~B}$ & $84 \mathrm{C}$ & $83 \mathrm{C}$ & $78 \mathrm{C}$ & $88 \mathrm{~B}$ & $10,68 \mathrm{~A}$ \\
\hline 30 dias de armazenamento & & $84 \mathrm{~B}$ & $79 \mathrm{C}$ & $78 \mathrm{D}$ & $66 \mathrm{D}$ & $80 \mathrm{~B}$ & $9,84 \mathrm{~B}$ \\
\hline Coeficiente de variação (\%) & & 3,43 & 5,45 & 3,17 & 4,78 & 5,71 & 5.66 \\
\hline
\end{tabular}

Médias seguidas da mesma letra maiúscula na coluna, não diferem entre si pelo teste de Scott-Knott a 5\%.

variações significativas, mas os valores percentuais de emergência de plântulas permaneceram elevados, acima de $80 \%$. Os resultados de emergência de plântulas em areia após deslintamento químico, beneficiamento em mesa de gravidade e durante o armazenamento diminuíram significativamente (Tabelas 1 e 2), sendo essas reduções mais acentuadas no ano agrícola de 2001. Tal redução pode ser devida aos cortes e abrasões, ao resíduo do ácido sulfúrico e ao processamento. A estocagem no campo não apresenta efeito imediato, mas pode prejudicar posteriormente a qualidade da semente quando armazenada por períodos superiores a 30 dias.

As sementes de algodão apresentaram valores menores de vigor, verificados nos testes de primeira contagem e índice de velocidade de emergência, antes e após a colheita mecânica (Tabelas 1 e 2) e pelo teste de emergência de plântulas em campo, antes da colheita (Tabela 2) e após a colheita (Tabela 1). Essa redução provavelmente é conseqüência da ação de patógenos, como Fusarium sp. que se encontravam em percentual elevado, logo após a colheita, 43 e $47 \%$ nos anos de 2001 e 2002. Nas etapas posteriores, houve redução na incidência de patógenos, principalmente após o descaroçamento e deslintamento, Tanaka e Paolinelli (1984) citam que o deslintamento químico reduz os microrganismos que se encontram na superfície das sementes. A incidência de Fusarium spp. foi reduzida de 2,4 e de 12,5 pontos percentuais após o deslintamento, nos anos agrícolas de 2001 e 2002, respectivamente, concordando com as observações de Patrício (1991).

No ano de 2001, as etapas de armazenamento de algodão em caroço, em fardos no campo, de descaroçamento e de deslintamento, não causaram perdas imediatas no vigor das sementes, quando esse foi avaliado pelos testes de primeira contagem, emergência de plântulas em campo e índice de velocidade de emergência (Tabela 1). Após o descaroçamento e deslintamento químico, os valores médios de vigor avaliados pelo índice de velocidade de emergência foram os mais altos ocorridos durante o experimento, devido à ocorrência de altas temperaturas nos meses de setembro e outubro $(29,8$ e $28,0^{\circ} \mathrm{C}$ ). Com o armazenamento, entretanto, as sementes apresentaram reduções significativas nos resultados dos testes de primeira contagem, envelhecimento acelerado, emergência de plântulas em campo e índice de velocidade de emergência. $\mathrm{O}$ vigor das sementes, quando avaliado pelo teste de primeira contagem, permaneceu acima de $70 \%$ somente até o segundo mês de armazenamento, sendo o seu valor reduzido praticamente à metade, $36 \%$, a partir do terceiro mês. Mesmo não se avaliando a incidência de danos mecânicos, observouse a presença de sementes com abrasões, cortes e amassamentos que, aliado ao elevado teor de óleo de sementes de algodão pode contribuir para perda de qualidade durante $\mathrm{o}$ armazenamento (Bragantini et al., 1974).

Da mesma forma, em 2002, não se verificou efeito do armazenamento temporário no campo sobre o vigor das sementes (Tabela 2), quando avaliado pelos testes de primeira contagem, envelhecimento acelerado, emergência e índice de velocidade de emergência de plântulas em campo, exceto aos 85 dias de armazenamento em fardo, nos testes de primeira contagem e envelhecimento acelerado. Nas etapas seguintes, observou-se decréscimo na qualidade das sementes que podem ser tanto conseqüência do descaroçamento como do 
deslintamento. O período de 30 dias em armazém convencional prejudicou o vigor das sementes e / ou possibilitou a manifestação de efeito latente do processamento sobre a qualidade fisiológica das sementes.

O teste de envelhecimento acelerado apresentou resultados mais baixos, detectando, após o deslintamento, a redução gradativa do vigor das sementes até o final do armazenamento. Esse teste foi considerado por Laposta (1991) e Freitas et al. (2000) como eficiente para separar lotes de sementes de algodão em diferentes níveis de vigor e, conseqüentemente, para mostrar a perda de qualidade fisiológica durante o armazenamento. Além da eficiência em diferenciar os níveis de vigor de sementes de algodoeiro, Torres (1998) verificou alta correlação entre o teste e a emergência de plântulas em campo. Amaral et al. (2001) também observaram que a perda de vigor em sementes de algodoeiro foi primeiramente verificada nos testes de estresse, como o envelhecimento acelerado.

Queiroga e Beltrão (1999) recomendam o armazenamento de sementes de algodão por no máximo oito meses, nas condições ambientais (valores médios de $26,9^{\circ} \mathrm{C}$ e $57 \%$ UR) e com teor de água abaixo de $10 \%$. Entretanto, Freire et al. (1999) observaram que sementes de algodoeiro armazenadas em ambientes com alta umidade relativa deterioram em curto espaço de tempo, chegando a perder a metade de seu valor inicial de germinação após 30 dias de armazenamento. Neste experimento, as sementes analisadas no ano agrícola 2001 permaneceram por seis meses após a colheita com germinação acima de 70\%. No ano agrícola 2002, cinco meses após a colheita, as sementes ainda apresentaram $84 \%$ de germinação. Nesse período, a temperatura variou de 27 a $29^{\circ} \mathrm{C}$ e a umidade relativa de 45 a $85 \%$.

$\mathrm{O}$ aumento do período de armazenamento proporcionou decréscimo linear na viabilidade e no vigor de sementes de quatro cultivares de algodoeiro, em trabalho de Freitas et al. (2000). Amaral et al. (2001), todavia, armazenaram sementes de algodoeiro da cultivar ITA-90 em ambiente sem controle de temperatura e de umidade relativa e verificaram que a porcentagem de germinação permaneceu acima do padrão para o comércio, até nove meses de armazenamento. Esses resultados favoráveis foram atribuídos, pelos autores, ao alto vigor inicial e baixo teor de água das sementes que reduziram a velocidade do processo deteriorativo. Essa relação entre vigor e potencial de armazenamento de sementes de algodoeiro também foi verificada por Pádua e Vieira (2001).

Neste estudo, pode-se constatar que as operações e procedimentos adotados após a colheita, pelos produtores da região, mantém a qualidade das sementes em nível aceitável até a semeadura do cultivo subseqüente, no mês de dezembro. Fato esse evidenciado pela porcentagem de germinação das sementes acima de $70 \%$, que é o mínimo para comercialização, até seis (ano agrícola 2001) e cinco meses após a colheita (ano agrícola 2002).

\section{CONCLUSÕES}

$\mathrm{O}$ armazenamento temporário de sementes de algodão em fardos no campo, por até 85 dias, não causa perda imediata na qualidade das sementes.

O descaroçamento mecânico não tem efeito prejudicial imediato sobre o vigor das sementes.

A porcentagem de germinação mantém-se dentro do padrão para o comércio de sementes de algodão por até seis meses após a colheita.

\section{REFERÊNCIAS}

AMARAL, J.O.R.; ALBUQUERQUE, M.C.F.E; CALDEIRA, S.A.F. Qualidade fisiológica de sementes deslintadas de algodoeiro durante o armazenamento. In: CONGRESSO BRASILEIRO DE ALGODÃO, 3,. 2001, Campo Grande. Anais... Dourados: Embrapa Algodão/ UFMS/ Embrapa Agropecuária Oeste, 2001. p. 941-943.

BORGES, L.C.; FERREIRA, D.F. Poder e taxas de erro tipo I dos testes Scott-Knott, Tukey e Student-Newman-Keuls sob distribuições normal e não normais dos resíduos. In: REUNIÃO ANUAL BRASILEIRA DA SOCIEDADE INTERNACIONAL DE BIOMETRIA, 47., 2002, Rio Claro. Resumos... Rio Claro, 2002. p.1-4.

BRAGANTINI, C.; MARCOS FILHO J.; ABRAHÃO, J.T.M.; GODOY, R. Avaliação do comportamento de sementes de algodoeiro (Gossypium hirsutum L.) durante o armazenamento. Anais da Escola Superior de Agricultura Luiz de Queiroz, Piracicaba, v.31, n.11, p. 175-185, 1974.

BRASIL. Ministério da Agricultura e Reforma Agrária. Regras para análise de sementes. Brasília: SNDA/DNDV/CLAV, 1992. 365 p.

FREIRE, E.C.; FARIAS, F.J.C.; WATANABE, P.A.; AGUIAR, P.H. Produção de sementes de algodoeiro no Mato Grosso. In: EMPRESA BRASILEIRADE PESQUISAAGROPECUÁRIA 1999. p. 40-48. (Boletim, 3).

FREITAS, R.A.; DIAS, D.C.F.S.; CECON, P.R.; REIS, M.S. Qualidade fisiológica e sanitária de sementes de algodão durante o armazenamento. Revista Brasileira de Sementes, Londrina, v.22, n.2, p.94-101, 2000.

FURLAN, S.H.; AMARAL, H.M.; BUENO, J.T.; MENTEN, J.O.M.; MORAES, M.H.D. Efeito de quatro fungicidas na incidência de Colletotrichum gossypii e Fusarium spp. em sementes de algodoeiro (Gossypium hirsutum L.) e sua relação com o vigor de sementes. Revista Brasileira de Sementes, Brasília, v. 8, n. 2, p. 
$67-75,1986$.

LAPOSTA, J.A. Comparação entre métodos para avaliação da qualidade fisiológica de sementes de algodão (Gossypium hirsutum L.). 1991. 61 f. Dissertação (Mestrado em Agronomia Fitotecnia) - Escola Superior de Agricultura de Lavras, Lavras, 1991.

LIMA, E.F.; CARVALHO, J.M.F.C.; CARVALHO, L.P. Comparação de métodos de análise sanitária e ocorrência de fungos em sementes de algodoeiro. Fitopatologia Brasileira, Brasília, v. 7, n. 3, p.401-406, 1982.

MAGUIRE, J.D. Speed of germination-aid in selection and evaluation for seedling emergence and vigor. Crop Science, Madison, v. 2, n. 1, p.176-177, 1962.

MARCOS FILHO, J. Teste de envelhecimento acelerado. In: KRZYZANOWSKI, F.C.; VIEIRA, R.D.; FRANÇA NETO, J.B. (Ed.). Vigor de sementes: conceitos e testes. Londrina: ABRATES, 1999. cap.3, p.1-24.

MATO GROSSO. Delegacia Federal de Agricultura - DFA/MT. Normas técnicas para produção de sementes. Cuiabá: DFA/MT, $1998.95 \mathrm{p}$.

MEDEIROS FILHO, S.; FRAGA, A. C.; QUEIROGA, V.P.; SOUSA, L.C.F. de. Efeito do armazenamento sobre a qualidade físiológica de sementes deslintadas de algodão. Ciência e Agrotecnologia, Lavras, v.20, n.3, p.284-292, 1996.

NAKAGAWA, J. Testes de vigor baseados na avaliação de plântulas. In: VIEIRA, R.D.; CARVALHO, N.M. (Ed). Testes de vigor em sementes. Jaboticabal: FUNEP; 1994. p. 49-85.
NEEGAARD, P. Seed pathology. London: MacMillan Press, 1977. $838 \mathrm{p}$.

PÁDUA, G.P.; VIEIRA, R.D. Deterioração de sementes de algodão durante o armazenamento. Revista Brasileira de Sementes, Londrina, v.23, n.2, p.255-262, 2001.

PATRÍCIO, F.R.A. Efeito do deslintamento à flama sobre a qualidade fisiológica e a sanidade de sementes de algodão. 1991. 122 f. Dissertação (Mestrado em Fitopatologia) - Escola Superior de Agricultura Luiz de Queiroz, Universidade de São Paulo, Piracicaba, 1991.

POPINIGIS, F. Fisiologia de sementes. Brasília: AGIPLAN. 1985. $289 \mathrm{p}$.

QUEIROGA, V.P.; BELTRÃO, N.E.M. Armazenamento. In: BELTRÃO, N.E.M. O agronegócio do algodoeiro no Brasil. Brasília: EMBRAPA, 1999. p. 457-469.

SILVA, C.M. Tecnologia de sementes de algodoeiro. In: SEMINÁRIO ESTADUAL DO ALGODOEIRO, 4. 1998, Cuiabá. Anais...Rondonópolis: Fundação MT, 1998. p. 87-90.

SOAVE, J. Diagnóstico da patologia de sementes de algodoeiro no Brasil. Revista Brasileira de Sementes, Brasília, v. 7, n. 1, p. 195-200, 1985.

TANAKA, M.A.S.; PAOLINELLI, G.P. Avaliação sanitária e fisiológica de sementes de algodoeiro produzidas em Minas Gerais. Revista Brasileira de Sementes, Brasília, v. 6, n.1, p. 71-81, 1984.

TORRES, S.B. Comparação entre testes de vigor para avaliar a qualidade fisiológica de sementes de algodão. Revista Brasileira de Sementes, Brasília, v. 20, n.2, p. 249-253, 1998. 